\title{
THE REASONS FOR FARMERS' RELUCTANCE TO PARCTICE THE AGRICULTURAL PROFESSION IN AL -ZAWIYA SUB-DISTRICT /SLAHALDIN GOVERNOATE
}

\author{
${ }^{1}$ Ahmed S. Abdullah ${ }^{2}$ Mohammed O. Shareef ${ }^{3}$ Abdalaziz H. Midhas ${ }^{1}$ \\ ${ }^{1-2}$ Economic and Agricultural Extension Dept, College of Agriculture, Tikrit \\ University. Iraq \\ ${ }^{3}$ Agricultural Extension and Techniques Transfer Dept, College of Agriculture and \\ Forestry, Mosul University. Iraq \\ Email:Ahmed.s.abdullsh@tu.edu.iq
}

\begin{abstract}
The study aimed to investigate the reasons that led the farmers 'abstention from agricultural work in Al-Zawiya sub-district in Baiji Governorate / Salah Al-Din Governorate in general. Then, find out the reasons Which led to farmers' 'abstention to work in every field of study. As well as determining the correlation relationship between the reasons for farmers, 'abstention and each of the following independent variables (age, educational level, years of work in agriculture, working in other occupations, attitude towards agricultural work, communication with sources of information). There for, the research community included (201) farmers reluctant to practice agricultural work. Thus, we chose a random sample of farmers at a rate of $(40 \%)$, so that the number of respondents who were subjected to the research reached (80) farmers who are not ready to work in agriculture. The results showed an increase in the abstention of farmers to farm work. We can conclude from this that there are real reasons that led to these results in an area, in spite fertile land for agriculture. The results also showed the existence of a significant correlation between the reasons for farmers' abstention from agricultural work and a set of independent variables. The researchers conclude the importance of these factors and the depth of their influence in increasing or decreasing causes of abstinence. We recommended the authorities, especially the Ministry of Agriculture, to develop solutions to the obstacles that make farmers stop agricultural work.
\end{abstract}

Keywords: reasons for reluctance, farmers, agricultural profession

Received: 23 / 12 / 2020, Accepted: 31 / 3 /2021

\section{INTRODUTION}

The agricultural sector is an important economic activity in most Arab countries, as it absorbs $30 \%$ of the total workforce, making it a major source of livelihood for a large proportion of the population. Agriculture represents an investment of available natural resources (Al-Aref, 2010), as it is the main industry in many societies. The developing world, as it supplies all other sectors with food and raw materials, and represents a major aspect in the exports of these societies and the source of their foreign exchange earnings .. (Saleh et al., 2004) Therefore, the economic importance of the agricultural sector is not limited only to countries with agricultural economies, but also for all Countries with Industrial Economies (Al-Mousawi, 2007) On the global economic stage, there are many crises and economic problems that have become the common denominator among 
all countries of the world, such as the problem of the global food crisis that quickly captured the attention of the world and at various international and international levels. Local levels to know the data of this crisis, determine its political, economic and social impacts, and to develop solutions and successful treatments. But in Iraq, the matter will be more complicated if we do not take into account the political, administrative and economic changes that have taken place in Iraq, and thus this matter has repercussions that affected the performance of the national economic sectors, especially agricultural (Abdul Latif, 2011). The increasing population growth in the world will lead to facing many challenges during the coming decades, and the main challenge is to provide quality food that leads to food security, and that Modern agricultural technology is the best way to do this (Murad, 2020).

Therefore, the process of rural agricultural development has become an important issue for developing countries, and this requires the achievement of development goals attention to it as well as setting awareness programs at all levels with modern agricultural methods that increase productive efficiency and increase the standard of living for their communities (Al Healyi and Aljar, 2020). The development of rural society, especially in developing countries, including Iraq, is the foundation of an essential step for the development of society as a whole (Alhafidh, 2019). The agricultural sector is one of the most important sectors in Iraq, despite its long-term impact by natural, human and political conditions that prevented the progress of this sector and its development to the required level. Strategies have been developed to improve its situation as the contribution of agricultural GDP to GDP continues to be very weak, and this made Iraq a market for products to other countries despite the availability of agricultural components in Iraq, but this sector still suffers from problems (Dawwood, 2020) The agricultural sector in Iraq is suffering from many challenges that require the state to face by direct and indirect financial, informational and technological support, and more investments., but what we see is that public and private direct investments, have witnessed a significant decline due to many economic, social and political factors as well as the Security and administrative and financial corruption issues, all that led to the deterioration of production and a decrease in the percentage of its contribution to the gross domestic product. Accordingly, Iraq has become dependent on global markets to provide food, I t means we should a treatment the problem in national security. (Khalaf, 2014). One of the most important problems facing the agricultural sector in general is the decline of water resources and urban sprawl at the expense of agricultural lands, as well as desertification, salinization of the soil and weak agricultural policy. There are other problems such as not using the application of modern technologies in agricultural production, transportation and marketing problems, pests and diseases affecting crops, and other problems (Abdullah and Khalaf, 2015)

Despite the attempts to develop this sector, it did not reach the level of ambition, the situation is indicates the underdevelopment of the agricultural sector, and not inability to cover the local market with the required production, we are becoming import most agricultural and animal products from abroad, there are emigration The people of the countryside to the city, unemployment and other problems. in spite of all the agricultural plans aimed at achieving food security, there is a great danger to the Iraqi 
economy by raising its agricultural exposure rate abroad as well as increasing its external debt and dependence on developed countries (Al-Nima, 2005).

The task of agricultural extension is not limited to persuading the peasants with the new scientific sayings, but rather it is in the continuous work to get them to actually adopt and implement them.

This is done by two interrelated processes: the first is the spread and transmission of the idea from its original sources to the farmers, and the second is the adoption process, which is the "mental process in which the individual passes from hearing the new idea until its final adoption." This means the individual goes through a series of stages: the awareness stage, the interest stage, and the evaluation stage The mental stage then the experimentation stage, the stage of adoption and application. Before entering these stages, there must be some problem or needs that the individual has to move him towards the stages. Farmers differ in the introduction of new experiences according to the time of the adoption process. The speed of adoption is affected by social, cultural, economic, and personal factors, and factors related to the nature and characteristics of the new experience (Al-Adly,1991) Agricultural extension work is based on the principle of organizing the people of the countryside for their benefit. It is concerned with multiple agricultural issues, focuses on local levels, and develops its program in light of changing field problems or the emergence of new needs. It has been proven by practical experience that it is the means by which large numbers of small and large farmers can be reached effectively. There are multiple examples of the successful application of the agricultural extension approach in several countries, such as farmers' development projects in Japan, Sri Lanka, Nepal, Ethiopia, China, Mexico, Syria, and others. The possibility of obtaining positive results and developing the agricultural sector is through: Education and collective organized work, represented in agricultural extension work (Gondal et al, 2019).

The extension work does not begin except from the reality of the existing conditions, but from how the farmers are, and the successful extension programs are those that are developed on the basis of farmers' problems, needs and realistic concerns (Al-Meligy and Abdullah, 2016).Extension programs are one of the main channels for addressing issues of food security and rural poverty, and these programs possess means of transferring modern technology to enable them to achieve their goals in addition to supervising the support and implementation of adult education programs in rural areas and helps farmers solve their problems and involve them in information programs and activities that They need,( Abbeam et al, 2018). The extension programs work to understand the farmers' perception about modern technology and their willingness to adopt it, by persuading them and changing their trends and if it is negative because the adoption of any agricultural technology is surrounded by a variety of economic, social and structural reasons that make the farmer take his position based on these programs (Olubukun and Abdidemi, 2021).

Therefore, agricultural guidance has a great role in educating and educating farmers, changing their directions and developing them through persuasion, so they realize that the knowledge and skills advised will benefit them. Salah al-Din Governorate is one of the Iraqi governorates in which it is and the largest part of it is a countryside, where it excels. Countryside to urban areas. The Tigris River divides the governorate into two halves, and it is the second governorate after Nineveh governorate in the production of 
grain, and the Baiji area is one of the largest districts in Salah al-Din governorate with a proportion (30\%) of the area of the governorate, and the Zawiya district is affiliated with the Baiji district, which is adjacent to the Tigris River, its environment is fertile and suitable for agriculture, the agricultural sector suffers There has been a severe deterioration that led to the reluctance of farmers to practice the profession of agriculture in recent years, and this very great reluctance is according to the reports of the Agriculture Directorate in Salah al-Din and the Zoya Division of Agriculture. An indication of this is the decrease in the production of agricultural crops that were previously grown in the region, but some of them were completely absent. The majority of the population has taken up occupations other than agriculture, and that the production of crops does not meet the basic need. This is a major agricultural problem for an area where fresh water is available and fertile land, so this research is to answer these following questions:

1- What are the reasons for the reluctance of farmers in Al-Zawiya sub- district to work in the agricultural profession in general?

2- What is the correlation between the independent variables and the reasons for farmers reluctance to work in the agricultural profession?

\section{THE RESEARCH AIMS}

1- Identity the level of reasons for the farmers abstention from working in the agricultural profession in Zawiya sub-district of Baiji district in general.

2-Identity the level of reasons for the farmers 'abstention from working in the agricultural profession in Zawiya sub-district of Baiji district in each field of study.

3- Identity the correlation relationship between the level of reasons for farmers 'abstention from working in the agricultural profession in Zawiya sub-district of Baiji district and the following independent variables (age, educational level, years of work in agriculture, profession, attitude about work in agriculture, contact with information sources)

4- Identify the reasons that led to the farmers abstention to working in the agricultural profession from the viewpoint farmers.

\section{THE RESEARCH IMPORTANC}

The importance of the research is focused on the increasing inability of the agricultural sector in Iraq to provide food, due to the deterioration of the components of agriculture, all of which reduces the possibility of competition with imported agricultural crops, and therefore this situation requires research to solve the problem, Then develop this sector of agriculture.

\section{THE RESEARCH HYPOTHESES}

1- There is no correlation between abstention farmers in agricultural profession working in ALZawiya sub-district and the age .

2 - There is no correlation between the reasons for the farmers 'abstention in agricultural profession working in ALZawiya sub-district and the educational level.

3 -There is no correlation between the reasons for the farmers 'abstention from agricultural profession working in AL Zawiya and the years of work in agriculture. 
4 -There is no correlation between the reasons for the farmers 'abstention from agricultural profession working in ALZawiya sub-district and professional work.

5- There is no correlation between the reasons for the farmers abstention from agricultural profession working in ALZawiya sub-district and the attitude about agricultural profession working

6 - There is no correlation between the reasons for the farmers 'abstention from agricultural profession working in AL Zawiya sub-district and contact with information sources.

\section{THE RESEARCH METHODOLOGY}

The descriptive approach was used to obtains the research objectives, as this approach is appropriate to access detailed data and facts about the reasons for abstaining from agricultural profession working .

\section{THE RESEARCH AREA}

Zawiya sub-district is a town located in the north of Salah al-Din Governorate, with a population of about 25,000 , and is located on the western side of the Tigris River facing the city of Zab. Administratively, the city belongs to the Baiji district, and therefore the area was chosen to conduct the research due to the large number of residents seeking work in agriculture despite the fertility of its lands and its proximity to the Tigris River.

\section{THE COMMUNITY AND SAMPLE RESEARCH}

The research community included all individuals who reluctance from agricultural profession working, whose a number is according to the statistics of the Agricultural Al-Zawiyah Division (211) farmers. After that, the initial test sample of (10) farmers was excluded, and it became number is (201) farmers who refrained from the profession of agriculture, a random sample of $40 \%$ was taken in a random way, so that the number of respondents is (80) farmers who are abstention to work in the agricultural profession.

\section{THE QUESTIONNAIRE PREPARATION}

A questionnaire form was designed as a means to collect data of the research, because it is great to the research methodology, as the questionnaire form are included two parts:

-The first part: includes questions about the independent variables, which are (age, educational level, years of work in agriculture, profession, attitude about work in agriculture, contact with information sources)

- The second part: represents the dependent variable, which is a set of reasons that led to the reluctance of farmers in the stages of the agricultural process, we were put the $(3,2,1)$ facing the scale paragraphs (large, medium, and few), as shown in Table No. (1) 
Table (1): The theoretical weights.

\begin{tabular}{|c|c|c|}
\hline The name of Field & $\begin{array}{c}\text { The number } \\
\text { of items }\end{array}$ & The theoretical weights \\
\hline $\begin{array}{c}\text { Reasons related to production requirements } \\
\text { (Input) }\end{array}$ & 11 & $11-33$ \\
\hline $\begin{array}{c}\text { Reasons for business costs } \\
\text { (operations) }\end{array}$ & 7 & $7-21$ \\
\hline $\begin{array}{c}\text { Reasons related to the final product and } \\
\text { marketing (output) }\end{array}$ & 8 & $8-24$ \\
\hline Total & $26-78$ \\
\hline
\end{tabular}

\section{THE VLIDITY AND RELIABILITY}

To achieve validity and reliability , the questionnaire was submitted in its initial form to professors specializing in the Department of Agricultural Extension at Tikrit University. After that, the experts' observations in terms of formulation and content were taken, the amendments were made based on the opinions of experts, then a preliminary test was made on a sample of (10) respondents to see the reliability and validity of the scale. We followed the method of Alfa . Kronbach in calculating the reliability, whose value was (0.858), and the value of the Validity coefficient was (0.926). The questionnaire was distinguished by good reliability and validity, it was appropriate for collecting data from the respondents.

\section{Measurement of independent factors}

These variables were measured as follows:

1- Age: It is measured by the number of years of age of the respondent at the time of data collection.

2-The educational level: it was measured with numerical values $(1,2,3,4,5,6,7,8)$ according to levels (illiterate, reading and writing, elementary, intermediate, secondary, preparatory, institute, college and high certificate )

3- Years of work in agriculture: This variable was measured by the number of previous years in agricultural work.

4- Occupation: This variable was measured with numerical values $(1,2,3)$ according to levels (worker, retired, employee).

5- Attitude towards work in agriculture: it was measured by numerical values $(1,2,3)$ according to levels (agree, neutral, disagree) for six items divided into two halves, one negative and the other positive. So the theoretical range of the variable is (6-18).

6- Information sources: measured by numerical values $(0,1.2,3)$ according to (always, sometimes, rarely, no contact) levels.

\section{THE STATISTICAL METHODS}

For data analysis, we used statistical analysis software (spss), which is suitable for descriptive research.

\section{THE RESULTS AND DISCUSSION}

The first objective: Determining the reasons level for farmers' abstention from agricultural work in the Zawiya, in general: 
The results showed that the highest value obtained by the respondents is (78) and the lowest value is (26), with an average of (60.6). The respondents were divided into three categories according to the range law, as shown in Table (2):

Table (2): Distribution of the respondents according to categories in general.

\begin{tabular}{|c|c|c|c|c|}
\hline \multicolumn{2}{|c|}{ The Categories } & The Numbers & $\%$ & X- \\
\hline lower category & $26-42$ & 18 & 22.5 & 60.6 \\
\hline Medium category & $43-59$ & 22 & 27.5 & $\mathrm{Sd}$ \\
\hline High category & $\begin{array}{c}\text { More than } \\
60\end{array}$ & 40 & 50 & \multirow{2}{*}{6.34} \\
\hline Total & & 80 & $100 \%$ & \\
\hline
\end{tabular}

Table (2) shows that $50 \%$ of the respondents were in the highest category for reasons of abstention, then the Medium category $27.5 \%$, while the low category ranked last with $22.5 \%$. It is clear from the aforementioned percentages that the highest category of reasons for abstinence came first, Perhaps the reason for this is that the reluctance of farmers in this region to practice the profession of agriculture is the result of real problems such as power cuts, lack of government support, high prices for agricultural supplies, in addition to importing crops without controls and their impact on local crop prices, and this makes agricultural work without economic benefit when compared to its costs And the effort expended in cultivating it, and this result is consistent with what he reached (Aziz and Ali, 2014)

The second objective: Determine the reasons level for farmers' abstention from agricultural profession working in the Zawiya sub-district, in each field of study:

1- Reasons about a production requirements (inputs): The results showed that the highest numerical value obtained by the two subjects (33) and the lowest value (11), with an average (23.8), the respondents were divided into three categories according to the law of the range and as shown in Table No 3:

Table (3) shows that $43.75 \%$ of the respondents were in the upper category, for reasons of abstinence in the field of inputs, then the intermediate group by $31.25 \%$, while the lower group ranked at last by $25 \%$. The reason for this, maybe that the reasons about production requirements (inputs) that most farmers suffer from it, so

Table (3): Distribution of respondents according to the categories of the input field.

\begin{tabular}{|c|c|c|c|c|}
\hline \multicolumn{2}{|c|}{ The Categories } & The Numbers & $\%$ & $\mathrm{X}-$ \\
\hline lower category & $11-18$ & 20 & 25 & 23.8 \\
\hline Medium category & $19-25$ & 25 & 31.25 & $\mathrm{Sd}$ \\
\hline High category & $26-33$ & 35 & 43.75 & \multirow{2}{*}{3.9} \\
\hline Total & & 80 & $100 \%$ & \\
\hline
\end{tabular}


these reasons they were distinguished by the realism, which are the important and main reasons for their abstinence in agricultural work in this field that appeared in the above tables This result is consistent with his findings (Aziz and Ali, 2014).

2- Reasons about the costs of work (operations):

The results showed that the highest value obtained by the two subjects (21) and the lowest value (7), with an average of (15.8). The respondents were divided into three categories according to the Law of Range and as shown in Table No. 4:

Table(4): Distribution of respondents according to categories and field of operations.

\begin{tabular}{|c|c|c|c|c|}
\hline \multicolumn{2}{|c|}{ The Categories } & The Numbers & $\%$ & $\mathrm{X}-$ \\
\hline lower category & $7-11$ & 24 & 30 & 15.8 \\
\hline Medium category & $12-16$ & 26 & 32.5 & $\mathrm{Sd}$ \\
\hline High category & $17-21$ & 30 & 37.5 & 2.8 \\
\hline \multicolumn{2}{|c|}{ Total } & 80 & $100 \%$ & 2.8 \\
\hline
\end{tabular}

Table (4) shows that $37.5 \%$ of the respondents were in the high category for reasons of abstinence, then the Medium category by $32.5 \%$, while the lower group ranked at least $30 \%$. This indicates that the reasons level for inaction in the field of operations is also high. This may be due to reasons about the labor costs, the wages of plowing, combating, fertilizing and fuel wages. These are real and large reasons that farmers suffer, they are the main reasons for their abstention working in farming. This result is inconsistent with his findings (Aziz and Ali, 2014)

3- Reasons about to the final product and marketing (outputs): The results showed that the highest value was obtained by the two subjects (24) and the lowest value (8), with an average of (14.4). The respondents were divided into three categories according to the range, and as shown in Table No 5:

Table (5): Distribution of respondents according to the output field categories.

\begin{tabular}{|c|c|c|c|c|}
\hline \multicolumn{2}{|c|}{ The Categories } & The Numbers & $\%$ & $\mathrm{X}-$ \\
\hline High category & $8-13$ & 25 & 31.25 & 14.4 \\
\hline Medium category & $14-19$ & 30 & 37.5 & $\mathrm{Sd}$ \\
\hline lower category & 20 -more & 25 & 31.25 & \multirow{2}{*}{2.11} \\
\hline Total & & 80 & $100 \%$ & \\
\hline
\end{tabular}

It is clear from Table (5) that $37.5 \%$ of the respondents were in the medium category, for reasons of abstention while the lower and upper category came with the same rate of $31.25 \%$. This indicates that the level of reasons for reluctance is average in the range of outputs. The reason for this may be that the reasons related to the final product, marketing, farms can handle some of them and bear their difficulties, especially since the security situation, which was considered the main obstacle in marketing, has 
gradually improved, as well as the recent government measures to stop importation and banking procedures in the disbursement of farmers' dues. For this reason, came The result is like this.

The third objective: to determine the correlation relationship between the level of reasons for farmers 'abstention from working in the agricultural profession in the Zawiya sub-district and each of the following factors (the age, educational level, years of agricultural work, agricultural land area, profession, attitude to work in agriculture, contacting information sources):

1- Age: the respondents were distributed according to the age variable into three groups, as shown in Table 6:

Table No. (6) shows that $50 \%$ of the respondents fall into the middle age group, then the low group by $31.25 \%$. There is no correlation between the level of reasons for abstinence and age. The Pearson correlation coefficient and its value (0.08) was used. Thus, the statistical hypothesis was accepted (there is no significant correlation between the level of reasons for farmers' abstention from agricultural work and age). The reason

Table (6): Distribution of the respondents according to age groups.

\begin{tabular}{|c|c|c|c|c|}
\hline The Categories & The Number & $\%$ & $\begin{array}{c}\text { The Average } \\
\text { Reluctance }\end{array}$ & $\mathrm{R}$ \\
\hline $27-40$ & 25 & 31.25 & 49.9 & 0.08 \\
\hline $41-54$ & 40 & 50 & 59.9 & The significant \\
\hline $55-68$ & 15 & 18.75 & 57.8 & not significant \\
\hline Total & 80 & $100 \%$ & & \\
\hline
\end{tabular}

may be that the reasons for abstaining from agricultural work are not about the age of farmers, but about problems to the reality of agricultural operations in the field of research .This result is inconsistent with his findings (Sayer \& Soliman, 2014).

2- The educational level: The respondents were distributed according to the educational level variable into eight categories, as shown in Table No 7.

Table (7) shows that 23.75 of the respondents from elementary graduates, which is the highest among the other categories of educational level, while the lowest percentage came in the category of high studies, at $5 \%$.

To obtain the correlation relationship between the level of reasons for abstinence and the educational level, Spearman's correlation coefficient was used, which was $(-0.36)$. thus, To test the significance of the correlation, the law (t) was used Where it was found to be inverse significance at the level of 0.01 , so, we are rejecting the statistical hypothesis, ( there is no significant correlation relationship between the two variables ) , we are accepting the alternative hypothesis that states that there is a significant relationship between the two variables. 
Table. (7): Distribution of the respondents according to the educational level.

\begin{tabular}{|c|c|c|c|c|}
\hline The Categories & The Number & $\%$ & $\begin{array}{l}\text { The Average } \\
\text { Reluctance }\end{array}$ & $\mathrm{r}$ \\
\hline Illiterate & 10 & 12.5 & 73.2 & \multirow{3}{*}{$0.36-$} \\
\hline Reads and writes & 10 & 12.5 & 69.2 & \\
\hline Elementary school & 19 & 23.75 & 65.3 & \\
\hline Secondary school & 13 & 16.25 & 68.4 & $\begin{array}{c}\text { The } \\
\text { significant }\end{array}$ \\
\hline High school & 8 & 10 & 63.4 & \multirow{5}{*}{ Significant** } \\
\hline Institute graduate & 6 & 7.5 & 57.1 & \\
\hline College graduate & 10 & 12.5 & 35.1 & \\
\hline High certificate & 4 & 5 & 30.2 & \\
\hline Total & 80 & $100 \%$ & & \\
\hline
\end{tabular}

** Correlation is significant at the 0.01 level

The reason for this may be that the higher the educational level of the farmers, they are able to overcome the reluctance that lead to refraining in the it .This result is consistent with his findings (Abdel Wahab \& Youssef, 2018).

3- Number of years of work in agriculture: The respondents were distributed according to the variable of years of work into three categories, as shown in Table No. $8:$

Table (8): Distribution of respondents according to the categories of years of work in agriculture.

\begin{tabular}{|c|c|c|c|c|}
\hline $\begin{array}{c}\text { The } \\
\text { Categories }\end{array}$ & $\begin{array}{c}\text { The } \\
\text { Number }\end{array}$ & $\%$ & $\begin{array}{c}\text { The } \\
\text { Average } \\
\text { Reluctance }\end{array}$ & r \\
\hline $5-14$ & 38 & 47.5 & 70.98 & $0.30-$ \\
\hline $15-24$ & 24 & 30 & 60.4 & \\
\hline $25-34$ & 18 & 22.5 & 50.3 & Significant \\
\hline Total & 80 & $100 \%$ & & Significant* \\
\hline
\end{tabular}

* Correlation is significant at the 0.05 level

Table (8) shows that $47.5 \%$ of the respondents are in the lowest category for years of work in agriculture with a general average of (17.5).In the statistical analysis, it was found that there is a relationship between the level of reasons for farmers abstaining from agricultural work and years of work in agriculture, and we used the Pearson correlation coefficient and its value (-0.30). Thus, we rejected the statistical hypothesis that (there is no statistically significant correlation between the level of reasons for farmers abstaining in agricultural work and years of work) and we accepted the alternative hypothesis for the existence of an inverse function relationship. The reason 
may be that farmers who have long years of agricultural work have a greater ability than others to deal and overcome problems in agricultural work, and this is caused by the accumulation of experience with them. This result is consistent with his findings (Sayer and Solomon, 2014).

4- the profession: The respondents were distributed according to the profession variable into three categories, as shown in Table 9:

Table (9) shows that $56.25 \%$ of the respondents are employees, and we did not find a correlation between the level of farmers 'abstention reasons from working in agriculture and profession., We found that the Spearman correlation coefficient was (0.29), and in order to test the relationship, the law (t) was used where It was found to be significant at (0.05) level. Thus, we reject the statistical hypothesis (there is no significant correlation between the level of reasons for farmers' reluctance to farming work and the profession) and accept the alternative hypothesis for the existence of a positive Significant relationship.

Table (9): Distribution of the respondents according to the profession categories.

\begin{tabular}{|c|c|c|c|c|}
\hline The Categories & $\begin{array}{c}\text { The } \\
\text { Number }\end{array}$ & $\%$ & $\begin{array}{c}\text { The } \\
\text { Average } \\
\text { Reluctance }\end{array}$ & $\mathrm{R}$ \\
\hline Worker & 15 & 18.75 & 40.1 & 0.29 \\
\hline Retired & 20 & 25 & 61.9 & The significant \\
\hline Employee & 45 & 56.25 & 69.1 & Significant* \\
\hline Total & 80 & $100 \%$ & & \\
\hline
\end{tabular}

* Correlation is significant at the 0.05 level

The reason may be that a large number of farmers from Al-Zawiya went to jobs to obtain stable and comfortable income without threats, as in the agricultural profession, so we notice that their position is with a high level of agricultural work abstinence .

5- The attitude towards agricultural work : The respondents were distributed according to the variable of the attitude towards agricultural working into three categories according to the law of the range , as shown in Table 10:

Table (10): Distribution of the respondents according to the categories of attitude towards agricultural work

\begin{tabular}{|c|c|c|c|c|c|}
\hline \multicolumn{2}{|c|}{ The Categories } & $\begin{array}{c}\text { The } \\
\text { Number }\end{array}$ & $\%$ & $\begin{array}{c}\text { The } \\
\text { Average } \\
\text { Reluctance }\end{array}$ & $\mathrm{R}$ \\
\hline Negative & $6-9$ & 50 & 62.5 & 68.8 & -0.39 \\
\hline Neutral & $10-13$ & 20 & 25 & 57.7 & The significant \\
\hline Positive & 14 -more & 10 & 12.5 & 40.9 & significant ** \\
\hline \multicolumn{2}{|c|}{ Total } & 80 & $100 \%$ & & \\
\hline
\end{tabular}

** Correlation is significant at the 0.01 level 
Table (10) shows that $62.5 \%$ of the respondents in the category have a negative tendency towards agricultural work. After statistical analysis, a strong relationship was observed between farmers ' abstention level and attitude towards agriculture. We used Spearman's correlation coefficient and its value (-0.39), and to test the significance of the relationship, the law (t) was used, as it was found to be significant at the level of 0.01 , which means that we reject the statistical hypothesis. (There is no correlation between the level of reasons for farmers 'reluctance to practice the profession of agriculture and the tendency towards agriculture) and acceptance of the alternative hypothesis for the existence of an inverse statistical relationship. The reason may be that farmers who have a negative attitude will have a higher level of reluctance to agricultural work than others, and therefore the rate at this level prompts them to reject agricultural work. This result is consistent with his findings (Abdel Wahab \& Youssef, 2018).

6- Contact with information sources: The respondents were distributed according to the information sources variable into three categories, as shown in Table 11:

Table (11) Distribution of respondents according to categories of information sources.

\begin{tabular}{|c|c|c|c|c|}
\hline The Categories & $\begin{array}{c}\text { The } \\
\text { Number }\end{array}$ & $\%$ & $\begin{array}{c}\text { The } \\
\text { Average } \\
\text { Reluctance }\end{array}$ & R \\
\hline $0-6$ & 53 & 66.25 & 69.34 & \multirow{2}{*}{-0.33} \\
\hline $7-12$ & 15 & 18.75 & 53.23 & The significant \\
\cline { 1 - 4 } $13-18$ & 12 & 15 & 33.9 & significant $*$ \\
\hline
\end{tabular}

* Correlation is significant at the 0.05 level

Table (11) shows that $66.25 \%$ of the respondents are in the low category for contacting information sources. After conducting the statistical analysis, we found that there is a correlation between the level of reasons for abstaining from agricultural work and contacting information sources. Spearman's correlation coefficient, whose value is $(-0.33)$, was used. We reject the statistical hypothesis (that there is no correlation between the level of reasons for abstaining from agricultural work and contacting information sources) and we accept the alternative hypothesis for the existence of an inverse significant correlation. The reason may be that farmers who have great access to information sources are more able to face and deal with the reasons for abstinence, and this reduces their impact on agricultural operations, while farmers with low connectivity do not have experience in facing challenges. This result is consistent with his findings (Abdel Wahab \& Youssef, 2018).

The fourth objective : The most important reasons that led to the farmers 'refusal to do agricultural work from the farmers 's viewpoint?

The order of the causes and problems from the viewpoint of the farmers themselves that led them to refrain from agricultural work, which were arranged in descending, as in Table No. 12: 
Table No. (12) shows that the most frequent and important reason is the trend of farmers in the research area towards government jobs and their preference for agricultural work, as it came primarily from their point of view. The reason for this may be: that government work salaries are guaranteed, unlike agricultural work, which involves many threats, so the farmer may lose his agricultural season for any of the risks of agricultural work. Additionally, government jobs are more comfortable than agricultural work. All this is due to the government's neglect of the agricultural sector, which is ranked second in the table. As for the most serious problem, it is the division of agricultural lands and their conversion into residential, and this is a major reason in the judiciary, and the profession of agriculture after several years, because the profits here are very large and economically feasible compared to agriculture. And this will lead to an agricultural disaster if there are no effective measures to address the problem by the competent authorities, and this is done with the support of government farms, as well as stopping the import of agricultural crops for an indefinite period.

Table (12): The order of the causes from the farmers' point of view, according to their frequency, in descending order.

\begin{tabular}{|c|l|c|}
\hline$\#$ & The problem & $\begin{array}{c}\text { The } \\
\text { frequency }\end{array}$ \\
\hline 1 & $\begin{array}{l}\text { Local people are turning to government jobs and leaving } \\
\text { farming }\end{array}$ & 58 \\
\hline 2 & Government neglect of the agricultural sector & 45 \\
\hline 3 & Dividing agricultural lands and converting them to residential & 40 \\
\hline 4 & Continuous electric Power Outages & 33 \\
\hline 5 & Competition of Imported agricultural crops & 30 \\
\hline 6 & The absence of any role for agricultural cooperative societies & 25 \\
\hline 7 & Transportation and marketing problems & 23 \\
\hline 8 & The spread of pests and agricultural diseases & 21 \\
\hline 9 & High prices for farm labor supplies & 20 \\
\hline 10 & Lack of man power(labor) & 19 \\
\hline
\end{tabular}

\section{CONCLUSIONS}

1 - The results showed an increase in the general level of seven weeks of farmers reluctance from agricultural work. We conclude that there are real reasons that led to this result, although the region has fertile lands for agriculture and fresh water, and it is in the Tigris River.

2- The results showed a variation in the levels of farmers' abstention from agricultural work according to the fields of study. The percentages of respondents in terms of the frequency of the inputs came in the first place, while the outputs came in the last place. This matter has many realistic reasons. We conclude from this, that the reasons related to production requirements (inputs) suffer from the majority of farmers as a result of their high costs, and the main reason was the abstention of farmers to practice the profession of agriculture.

3-The results showed that there is a significant correlation between the level of the farmers ' abstention from agricultural work and each of the following factors: 


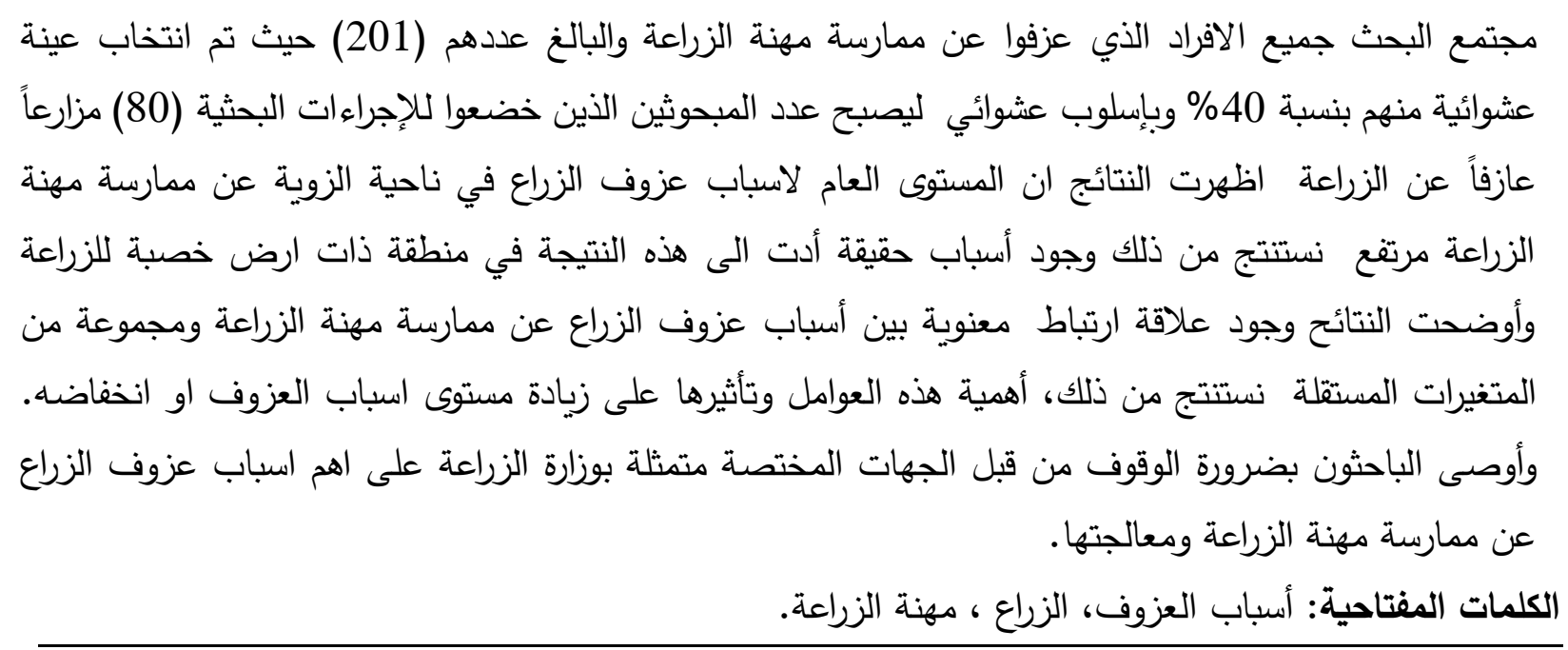
تاريخ استلام البحث:23 / 12 /2020، وقبوله: 2021/3/31

\section{REFERENCES}

Abbeam ,G.D., Ehiakpor, D. S. \& R. Aidoo , (2018), Agricultural extension and its efects on farm productivity and income: insight from northern ghana, Agriculture and Food Security, 7(74), 1-10.

Abdel latif, Z. A. (2011), Analysis of the Agricultural Sector in Iraq and the Reasons for Its Deterioration for the Period From (1990-2010) and Proposals for Its Development, ministry of planning/central statistical organization/ statistical training and research center, Iraq: 2.

Abdel Wahab, R. R \& S. A. Youssef, (2018), Obstacles facing agricultural development from the viewpoint of agricultural employees in Salah al-din governorate, Tikrit University Journal of Agricultural Sciences, 18(4),179-189.

Abdullah, K. A \& Khalaf ,S.Z. (2015), The problems facing grain farmers in the fallujah district, Anbar University Journal for Human Sciences, (1), 422-428.

Al Healyi , A.R.D \& N.A.Aljarjar (2020) The role of agricultural extension centers in rural developmet in iraq, Mesopotamia Journal of Agricultural , 48 (4), 62-64.

Al-Adly, A. A, (1991) , Fundamentals of Agricultural Extension Science, new publications house, Alexandria, Egypt. P: 5

Al-aref, J. S, (2010), Agricultural Planning and Development, first edition, dar al-raya publishing and distribution amman, Jordan. P: 95.

Alhafidh , A.Z.Y, (2019), Farmers knowledge level of potato crop cultivation in rabia sub- district / nineveh governorate , Mesopotamia Journal of Agricultural , 47 (1), 1-11.

Al-meligy , I. B \& Abdullah, H.H. (2016). The extension needs of knowledge for farmers by methods of optimal handling of green beans in the Tanta center gharial governorate, extension programs research department - institute for agricultural extension and rural development research center for agricultural research, Journal of Agricultural Economics, mansoura university,7(10), 992-998.

Al-mousawi, R. H. A, (2007), Agricultural Economics, al-taif printing, Baghdad, Iraq. P. 3 
Al-nima, A. W. M. (2005). The Role of Technical Progress in the Development of the Agricultural Sector in Iraq, M.Sc. thesis, Board of the college of administration and economics, University of Mosul. P. 3-7.

Aziz, J. M \& Ali, M.K. (2014). Reasons for cotton growers reluctance to cultivate the crop in hawija district in kirkuk governorate, Tikrit University Journal of Agricultural Sciences, special issue of the events of the third specialist, 412-413.

Dawood, H.S (2020) Determinants of agricultural production development in iraq for the period (1985-2016) an analytical economic study, Mesopotamia Journal of Agricultural ,124(39), 225-224 .

Gondal, A.S and Ashraf, G. H. and Hassan, Z.Y. (2019), Handbook of Agricultural Extension, science press, Pakistab. P. $1-20$.

Khalaf, B. J, (2014), The importance of agricultural investment in achieving food security in iraq, Journal of the Baghdad College of Economic Sciences, University, special issue of the fifth scientific conference, 3 .

Murad , H.S (2020), Knowledge level of agricultural employees in duhok directorate on integrated pest management , Mesopotamia Journal of Agricultural, 48 (2),114.

Olubukun, I .J \& Abidemi T.O. (2021). Factors influencing arable crop farmers willingness to adopt bio-organic technology in ondo state, nigeria , Journal of Agricultural Extension, 25 (1),18.

Saleh, S. M ., Al-Tanoubi, M. O, \& Azmi, S, M, (2004). Agricultural Extension Basics and Applications, alexandria book center, first edition, Egypt. P. 416.

Sayer, N. A. \& M. A. Suleiman, (2014), Reluctance of rice farmers in the levantine district to agriculture, Al-Qadisiyah Agricultural Journal, 1(4), 77-78. 